\title{
Isoleucine and Valine Metabolism of Escherichia coli
}

\author{
XV. Biochemical Properties of Mutants Resistant to Thiaisoleucine
}

\author{
A. SZENTIRMAI, ${ }^{1}$ M. SZENTIRMAI, ${ }^{1}$ AND H. E. UMBARGER \\ Department of Biological Sciences, Purdue University, Lafayette, Indiana 47907
}

Received for publication 24 February 1968

\begin{abstract}
Thiaisoleucine-resistant mutants of Escherichia coli strain K-12 which exhibited reduced isoleucyl soluble ribonucleic acid synthetase activity were isolated. Resistance was apparently achieved by the selection of a synthetase with a 10-fold decrease in apparent affinity for thiaisoleucine. This mutation also resulted in a 2.5-fold decrease in apparent affinity for the natural substrate, L-isoleucine, and less activity than found in wild type. The mutants grew more slowly than wild type and were derepressed for three of the five enzymes in the pathways to isoleucine and valine.
\end{abstract}

In the preceding paper $(17)$, it was reported that thiaisoleucine (2-amino-3-methylthiobutyric acid) prevented the growth of strain K-12 of Escherichia coli and that the growth inhibition was reversed by isoleucine at a concentration one-tenth that of the inhibitor. Thiaisoleucine was found to be a weak inhibitor of threonine deamination. It also interfered with the formation of isoleucyl sRNA and it underwent transamination with $\alpha$-ketoglutarate as the amino acceptor. This paper describes a series of mutants that are resistant to thiaisoleucine. Evidence is presented that they have altered isoleucyl soluble ribonucleic acid (sRNA) synthetases and that they have derepressed levels of three of the five enzymes that are involved in the biosynthesis of isoleucine and valine. These properties are of interest in view of the finding of Neidhardt and his co-workers $(4,10)$, who examined two of these five enzymes in cells with restricted valyl sRNA synthetase activity. Under these conditions there was derepression of both enzymes, including one, acetohydroxy acid synthetase, which was not derepressed in the mutants described here.

\section{Materials AND Methods}

The methods of cultivation of the organisms, the preparation of the extracts, the assays for threonine deaminase and for transaminase $B$, and the charging assay for the aminoacyl sRNA synthetases were described in the previous paper (17). A modified test for identifying the aminoacyl sRNA synthetases in diethylaminoethyl (DEAE)-cellulose column fractions is described below. Acetohydroxy acid synthe-

${ }^{1}$ Present address: Research Institute for Pharmaceutical Chemistry, Budapest, Hungary. tase activity was assayed by determining the amount of acetolactate formed as described by Størmer and Umbarger (16). Acetohydroxy acid isomeroreductase was determined by following reduced nicotinamide adenine dinucleotide phosphate $\left(\mathrm{NADPH}_{2}\right)$ disappearance at $30 \mathrm{C}$ in a Gilford model 2000 recording spectrophotometer. The complete system contained, in $0.5 \mathrm{ml}$ : potassium phosphate $(p \mathrm{H} 7.5), 50 \mu$ moles; magnesium chloride, $1.5 \mu$ moles; $\mathrm{NADPH}_{2}, 70$ m $\mu$ moles; $\alpha$-acetolactate, $2.5 \mu$ moles; and crude extract protein, 100 to $200 \mu \mathrm{g}$. The decrease in optical density was followed for $2 \mathrm{~min}$, and the observed rate was corrected for the rate of $\mathrm{NADPH}_{2}$ disappearance due to oxidase activity of the extracts. Dihydroxy acid dehydrase activity was assayed by using a reaction mixture containing, in $1 \mathrm{ml}$ : potassium phosphate $(p \mathrm{H} \mathrm{8.0),} 100 \mu$ moles; magnesium chloride, 10 $\mu$ moles; $\alpha, \beta$-dihydroxyisovalerate, $20 \mu$ moles; and crude extract protein, about $1 \mathrm{mg}$.

Owing to the difficulty in stabilizing the enzymatic activities, assays for all the biosynthetic enzymes, except that for the isomeroreductase, were performed immediately after the extracts were prepared. The isomeroreductase was much more stable and was assayed after the other assays had been completed. Radioactivity was determined in a NuclearChicago liquid scintillation spectrometer (model 725).

For the isolation of thiaisoleucine-resistant mutants, a $100-\mathrm{ml}$ culture of $E$. coli $\mathrm{K}-12$ in minimal medium containing initially $0.01 \%$ glucose was incubated overnight with shaking at $37 \mathrm{C}$. After incubation, glucose was added to yield $0.5 \%$, and $0.5-\mathrm{ml}$ samples were placed into each of 10 sterile Klett tubes. The tubes were incubated for $24 \mathrm{hr}$ at $37 \mathrm{C}$ in a tissue culture roller drum (New Brunswick Scientific Co., New Brunswick, N.J.), and then $4.5 \mathrm{ml}$ and minimal medium containing $3 \times 10^{-3} \mathrm{M}$ thiaisoleucine was added. Incubation was continued for an additional $72 \mathrm{hr}$. From each culture, $0.5 \mathrm{ml}$ was 
inoculated into $4 \mathrm{ml}$ of fresh medium containing $5 \times 10^{-3} \mathrm{M}$ thiaisoleucine. After 2 days at $37 \mathrm{C}, 1$ $\mathrm{ml}$ from each culture was mixed with $12 \mathrm{ml}$ of minimal agar containing $10^{-3} \mathrm{M}$ thiaisoleucine and a pour plate was prepared. The plates were incubated for 3 days, at which time several small colonies became visible. One colony from each plate was transferred to a nutrient agar slant. Cultures from three tubes, tentatively designated Tir-6, Tir-7, and Tir-8, were chosen for additional study.

Racemic $\alpha, \beta$-dihydroxyisovaleric and $\alpha$-acetolactic acids (the latter as the $\alpha$-acetoxy, ethyl ester) were obtained from Reef Laboratory (Lafayette, Ind.). Diethylaminoethyl-cellulose was Cellex-D from BioRad Products, Inc. (Richmond, Calif.). Before use, it was treated by the method of Shepherdson and Pardee (14). All other materials were the same as described in the preceding paper (17).

\section{RESULTS}

Growth of the thiaisoleucine-resistant (Tir) mutants. After isolation, the thiaisoleucineresistant mutants were examined for some of the properties exhibited by the parent K-12 strain. A very weak uptake of dye was exhibited by several of the strains, including strain Tir-8, instead of the metallic sheen expected of $E$. coli when grown on Levine's EMB lactose agar plates. However, this property was not due to a lactosenegative character, but apparently to the slow growth of these strains, since a glucose-nutrient medium prepared with eosin and methylene blue yielded similar results. Like the parent strain, all the Tir strains were inhibited by valine and were sensitive to MS-2 phage.

When strains Tir-6, Tir-7, and Tir-8 were grown in minimal medium with and without thiaisoleucine, strains Tir-6 and Tir-7, although growing as well or better than the parent strain, were still somewhat sensitive to thiaisoleucine
(Fig. 1A and B). In contrast, Tir-8, a slow-growing strain, was virtually unaffected by $5 \times 10^{-3}$ $M$ thiaisoleucine (Fig. 1C).

Effect of the Tir mutation on the level of isoleucine and valine forming enzymes. To determine whether there was any alteration in the endproduct sensitivity of either threonine deaminase or of acetohydroxy acid synthetase, or whether the enzymes were derepressed, cells grown in minimal medium were examined. Both Tir-7 and Tir-8 extracts exhibited threonine deaminase and acetohydroxy acid synthetase activities which were as sensitive to end-product inhibition as those in the wild-type extract. The activities of three of the five enzymes, however, were greater in the mutant extracts than in the wild-type extract (Table 1). Of the two that were less active in the mutants, only the acetohydroxy acid synthetase could be expected to be less active in slowly growing strains, because it is a less stable enzyme.

TABLE 1. Levels of the isoleucine- and valineforming enzymes in Escherichia coli $\mathrm{K}-12$ and two thiaisoleucine-resistant mutants

\begin{tabular}{|c|c|c|c|}
\hline \multirow{2}{*}{ Enzyme } & \multicolumn{3}{|c|}{ Specific activity ${ }^{a}$} \\
\hline & $\mathrm{K}-12$ & Tir-7 & Tir-8 \\
\hline Threonine deaminase.... & 0.088 & 0.284 & 0.575 \\
\hline $\begin{array}{c}\text { Acetohydroxy acid syn- } \\
\text { thetase } \ldots \ldots \ldots \ldots \ldots\end{array}$ & 0.148 & 0.093 & 0.062 \\
\hline $\begin{array}{l}\text { Acetohydroxy acid isom- } \\
\text { eroreductase } \ldots \ldots \ldots \ldots\end{array}$ & 0.177 & 0.082 & 0.038 \\
\hline $\begin{array}{l}\text { Dihydroxy acid dehy- } \\
\text { drase } \ldots \ldots \ldots \ldots \ldots \ldots\end{array}$ & 0.028 & 0.095 & 0.125 \\
\hline Transaminase B...... & 0.095 & 0.143 & 0.174 \\
\hline
\end{tabular}

a Expressed as micromoles per minute per milligram of protein.

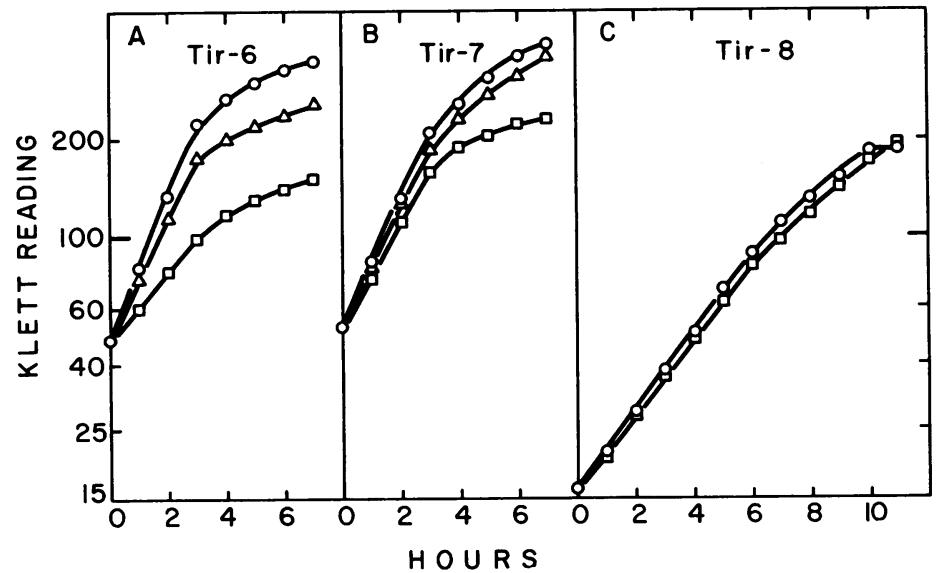

FIG. 1. Growth of three thiaisoleucine-resistant mutants in the presence and absence of thiaisoleucine. Symbols: $\bigcirc$, minimal medium; $\triangle$, same, containing $10^{-3}$ M thiaisoleucine; $\square$, same, containing $5 \times 10^{-3}$ M thiaisoleucine. A Klett reading of 100 represents $204 \mu \mathrm{g}$ (dry weight) of cells per $\mathrm{ml}$. 
The isomeroreductase is relatively stable; therefore, decreased activity in thiaisoleucine-resistant mutants suggests an actual repression (in contrast to mere absence of derepression) of these two enzymes.

Of interest is the fact that derepression of threonine deaminase, dihydroxy acid dehydrase, and transaminase $B$ and repression of acetohydroxy acid synthetase and isomeroreductase is exactly the pattern seen when $E$. coli $\mathrm{K}-12$ is grown under conditions of limiting isoleucine (3). Since the growth rates of Tir mutants are not restored to wild-type rate, nor is threonine deaminase repressed to the level of minimal-grown wild type by adding exogenous isoleucine (3), it seems reasonable to conclude that the signal, "isoleucine in excess," cannot be generated as efficiently in the mutants as in the wild strain.

Effect of the Tir mutation on the level of isoleucyl sRNA synthetase. In view of the demonstration by Eidlic and Neidhardt (4) that the activation of valine was necessary for it to participate in multivalent repression of the isoleucine-valine biosynthetic enzymes, it was of interest to determine whether the Tir mutants were faulty in isoleucyl sRNA synthetase activity. Extracts of both Tir-7 and Tir- 8 had only a fraction of the activity shown by an extract of the parent strain (Table 2). In contrast, the leucyl sRNA synthetase was the same in the mutant and wild-type strains. Also, the isoleucyl sRNA synthetase activities of the mutants, although lower than that in wild type, were much less sensitive to inhibition by thiaisoleucine (Table 2). Thus, the Tir mutation has probably affected a structural gene for the synthetase, resulting in the formation of an altered protein.

To determine the effect of substrate concentration on the formation of isoleucyl SRNA in crude extracts of strains $\mathrm{K}-12$ and Tir-8, a range of $\mathrm{L}$-isoleucine concentrations between $10^{-6}$ and

\begin{tabular}{|c|c|c|c|}
\hline \multirow{2}{*}{ Strain } & \multicolumn{2}{|c|}{ Isoleucyl sRNA synthetase } & \multirow{2}{*}{$\begin{array}{l}\text { Leucyl sRNA } \\
\text { synthetase } \\
\text { specific } \\
\text { activity }\end{array}$} \\
\hline & $\begin{array}{l}\text { Specific } \\
\text { activity }^{a}\end{array}$ & $\begin{array}{l}\text { Inhibition with } 5 \times \\
10^{-4} \mathrm{M} \text { thiaisoleucine }\end{array}$ & \\
\hline & & $\begin{array}{l}\% \\
35\end{array}$ & 00010 \\
\hline Tir-7. & 0.00009 & 7 & 0.0010 \\
\hline Tir -8 & 0.0002 & 2 & 0.0012 \\
\hline
\end{tabular}

a Substrate concentration, $2 \times 10^{-5} \mathrm{M}$; specific activity expressed as micromoles per minute per milligram of protein.
$10^{-2} \mathrm{M}$ was employed. A striking difference between the two strains was observed when concentrations in the range $\left(10^{-6}\right.$ to $\left.10^{-5} \mathrm{M}\right)$ commonly used in amino acid activation studies were employed (Fig. 2). If the L-isoleucine concentration was increased to $10^{-2} \mathrm{M}$, however, the radioactivity retained in the sRNA fraction increased about fivefold with the wild-type extract. At that substrate concentration, incorporation with the mutant extract had so increased that there was almost no difference between the two extracts. Assuming that only an assay employing a substrate concentration of about $10^{-5} \mathrm{M}$ was valid for isoleucyl sRNA synthetase, the crude extract of strain Tir-8 appeared to be nearly devoid of activity. If the enzyme in strain Tir- 8 had a reduced affinity for isoleucine, its activity might have been masked by the greater retention of counts in the sRNA fraction that occurred at high isoleucine concentrations with extracts of both strains. [When isoleucine activation was measured in the wild-type extract by the hydroxamate method of Loftfield and Eigner (9), no

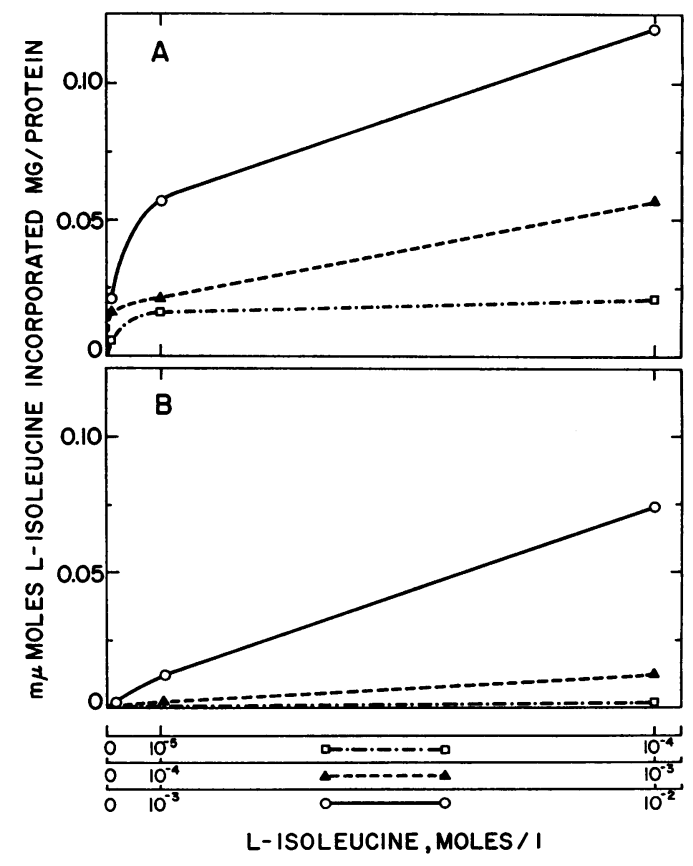

FIG. 2. Effect of substrate concentration on the incorporation of ${ }^{14} C$ - $L$-isoleucine into the soluble $R N A$ fraction by crude extracts of Escherichia coli strains $K-12$ and Tir-8. (A) Extract prepared from strain $K-12$; (B) extract prepared from strain Tir-8. The three curves in each graph are plotted on three different scales as indicated at the bottom of the figure. Thus, in each graph, the same $10^{-4} \mathrm{M}$ point is represented three times, once on each curve. 
indication of this interfering activity was observed.] However, only a barely detectable level was observed in the Tir-8 extract, even at the high substrate concentrations tested. To compare the $K_{\mathrm{m}}$ for L-isoleucine of the mutant and wildtype enzymes, a separation from the interfering activity was undertaken.

Separation of isoleucyl, valyl, and leucyl sRNA synthetases of $E$. coli on diethylaminoethyl cellulose columns. A preliminary separation of inactive protein was obtained by acidifying $40 \mathrm{ml}$ of crude extract from strain $\mathrm{K}-12$ to $p \mathrm{H} 4.95$ with $1 \mathrm{~N}$ acetic acid and centrifuging at $15,000 \mathrm{rev} / \mathrm{min}$ for $20 \mathrm{~min}$ in a Sorvall RC-2 centrifuge with an SS-34 rotor. The supernatant fluid was adjusted to $p \mathrm{H} 7$ and placed on a column $(20 \times 250 \mathrm{~mm})$ of diethylaminoethyl cellulose which had been equilibrated with $20 \mathrm{~mm}$ phosphate buffer $(p \mathrm{H} 7)$ containing $6 \mathrm{~mm}$ mercaptoethanol. The column was washed with $20 \mathrm{ml}$ of the same buffer and eluted at a rate of $25 \mathrm{ml}$ per hr with $600 \mathrm{ml}$ of phosphate buffer with a linear concentration gradient between $20 \mathrm{~mm}$ and $0.5 \mathrm{M}$. Fractions of $3 \mathrm{ml}$ were collected; the protein in each fraction and the capacity to transfer $\mathrm{L}$-valine, $\mathrm{L}$-isoleucine, and L-leucine to sRNA in selected fractions was determined by using a modified assay. Effluent samples of $0.1 \mathrm{ml}$ were placed in each of four tubes containing: Tris-chloride $(p \mathrm{H} \mathrm{8.0),} 14 \mu$ moles; sRNA, $0.14 \mathrm{mg}$; disodium magnesium ethylenediaminetetraacetate (EDTA), $1.75 \mu$ moles; sodium adenosine triphosphate, 1.4 $\mu$ moles; glutathione, $0.5 \mu$ mole; and magnesium chloride, $0.8 \mu$ mole in a total volume of $0.14 \mathrm{ml}$. The four tubes also contained one of the following: $0.4 \mathrm{~m} \mu$ mole $\left(4 \times 10^{5}\right.$ counts $\left./ \mathrm{min}\right)$ of uniformly labeled ${ }^{14} \mathrm{C}$-L-leucine, ${ }^{14} \mathrm{C}$-L-valine, or ${ }^{14} \mathrm{C}$ $\mathrm{L}$-isoleucine, or $40 \mathrm{~m} \mu$ moles $\left(4 \times 10^{6}\right.$ counts $/$ min) of uniformly labeled ${ }^{14} \mathrm{C}$-L-isoleucine. Two concentrations of isoleucine were used to distinguish between isoleucyl sRNA synthetase activity and that of the second, interfering component. After $10 \mathrm{~min}$ at $37 \mathrm{C}, 0.2-\mathrm{ml}$ samples were applied to filter-paper squares and extracted in the usual way.

Chromatography of the wild-type extract resulted in the partial separation of the amino acyl sRNA synthetases reacting with low levels of the branched-chain amino acids (Fig. 3A). When a high concentration of $\mathrm{L}$-isoleucine was used, two fractions of activity were found. The component which catalyzed an appreciably greater incorporation of L-isoleucine into the SRNA fraction at the higher substrate concentration was eluted at about the same time at which the leucyl sRNA synthetase was eluted.

When an extract of strain Tir- 8 was fractionated in the same way, essentially the same elution pat- tern (Fig. 3B) was observed, except that the component identified as isoleucyl sRNA synthetase was only about one-tenth as active as it was in the wild-type preparation. In fact, greater activity for charging sRNA at low levels of isoleucine was found in the fraction migrating with leucyl sRNA synthetase than in the isoleucyl sRNA synthetase fraction itself. Thus, it appeared that most of the activity exhibited by the mutant extract for the charging of sRNA with the preparation of L-isoleucine used in this study (as shown in Table 2) was due to a second component which may not be an isoleucyl sRNA synthetase and which appears to have been unaffected by the Tir- 8 mutation. (The interfering activity may be due to contaminating L-leucine in the $\mathrm{L}$ isoleucine preparation. The activity which is "saturated" with L-isoleucine only with difficulty appeared in the same effluent fractions as did the leucyl sRNA synthetase activity. Charging by this activity of sRNA with isoleucine is strongly suppressed, but not eliminated, by adding L- or DL-leucine.)

Comparison of wild-type and mutant isoleucyl $s R N A$ synthetases. To determine whether the wild-type and mutant enzymes differed in the $K_{\mathrm{m}}$ for isoleucine, a loading assay was performed with the partially purified isoleucyl sRNA synthetases from strains $\mathrm{K}-12$ and Tir- 8 in the presence of several concentrations of isoleucine and thiaisoleucine. The inhibition of isoleucyl sRNA formation by thiaisoleucine was competitive (Fig. 4 and 5), as would be expected if thiaisoleucine also served as a substrate for the enzyme. The $K_{\mathrm{m}}$ values determined from the data were $6.6 \times 10^{-7} \mathrm{M}$ for the wild-type enzyme and $17.5 \times 10^{-7} \mathrm{M}$ for the mutant. When the graphic method of Dixon (2) for the determination of $K_{\mathrm{i}}$ was employed by using the same and other data (i.e., a plot of $1 / v$ versus thiaisolecuine concentration), the value for $K_{\mathrm{i}}$ for wild-type and mutant enzymes was 4.3 and $52 \times 10^{-6} \mathrm{M}$, respectively. Thus, it appears that, although there was a 2.5-fold loss in affinity for the natural substrate as a result of the Tir mutation, there was a greater than 10 -fold decrease in sensitivity to the analogue.

Isoleucine acceptor activity of $S R N A$ prepared from strains $K-12$ and Tir-7. While the thiaisoleucine-resistant strains were characterized by having reduced isoleucyl sRNA synthetase activities, it seemed worthwhile to compare the level of isoleucine acceptor activity in the wild type with that in one of the mutants. For this purpose, the sRNA was prepared from strain Tir-7. It was then tested with both wild-type and Tir-7 crude extracts. No difference was demonstrated in the isoleucine acceptor capacities of the two prepara- 

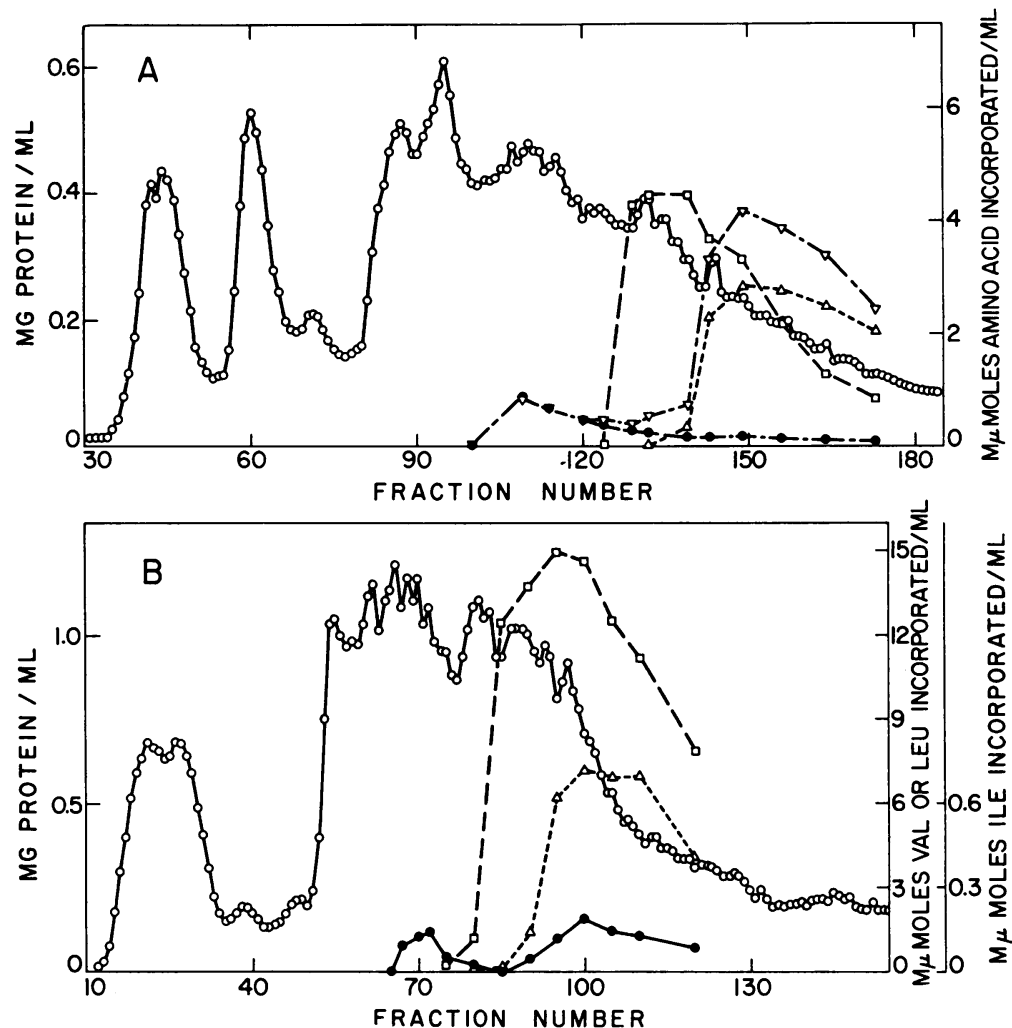

FIG. 3. Elution patterns of the $\mathrm{pH}$ 4.95-soluble fraction of a crude extract of Escherichia coli strains $K$ - 12 and Tir-8 from diethylaminoethyl cellulose obtained by eluting with the linear gradient described in the text. $(A)$ Strain $K-12 ;(B)$ strain Tir-8. Symbols: $\bigcirc$, protein; $\square$, valyl soluble $R N A$ synthetase activity; $\triangle$, leucyl soluble RNA synthetase activity;, isoleucine incorporated by using $1.67 \times 10^{-6} \mathrm{M}$ L-isoleucine $; \nabla$, isoleucine incorporated by using $1.67 \times 10^{-4}$ M L-isoleucine.

tions (Table 3). Whereas these results did not reveal an alteration in the level of a minor species of isoleucine acceptor sRNA (if several species do exist), they indicated that the lesion did not grossly affect the level of isoleucine sRNA, as the hisR mutation in Salmonella typhimurium affected the level of the histidine sRNA (15).

Charging of isoleucine sRNA with thiaisoleucine by partially purified isoleucyl sRNA synthetase. Because radioactively labeled thiaisoleucine was not available, it was not possible to determine directly whether thiaisoleucine was transferred to isoleucyl sRNA. However, a test for protection against oxidation by periodate by the analogue could be used which was similar to that used by Ezekiel (5) with $p$-fluorophenylalanine to indicate charging of an sRNA component. A $2.25-\mathrm{mg}$ sample of $E$. coli sRNA was incubated with $0.1 \mathrm{mg}$ of the partially purified isoleucyl sRNA synthetase for $30 \mathrm{~min}$ at $37 \mathrm{C}$ in a $1.5-\mathrm{ml}$ reaction mixture containing (in micromoles): adenosine triphosphate, 40; Mg EDTA, 30; Tris-chloride
( $p \mathrm{H}$ 8.0), 225; glutathione, 9; $\mathrm{KCl}, 9 ; \mathrm{MgCl}_{2}, 9$; and, where indicated, L-isoleucine, 5 , or thiaisoleucine, 50. The reaction was stopped with $3.5 \mathrm{ml}$ of cold ethyl alcohol. After brief centrifuga-

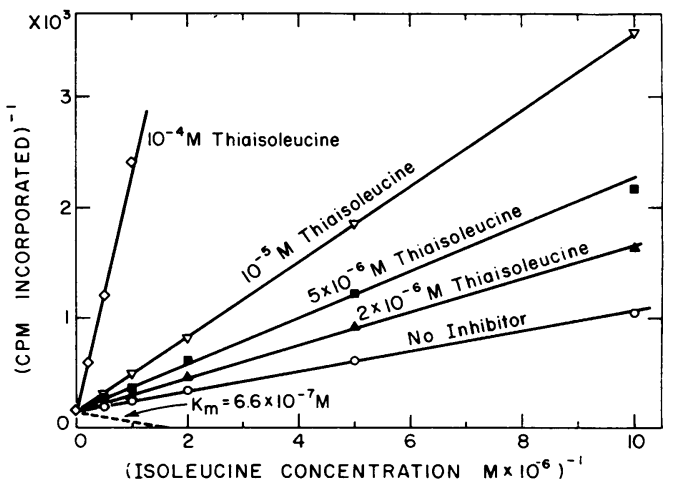

FIG. 4. Effect of thiaisoleucine on the charging of isoleucine soluble RNA by isoleucyl soluble RNA synthetase prepared from Escherichia coli strain $K-12$. 


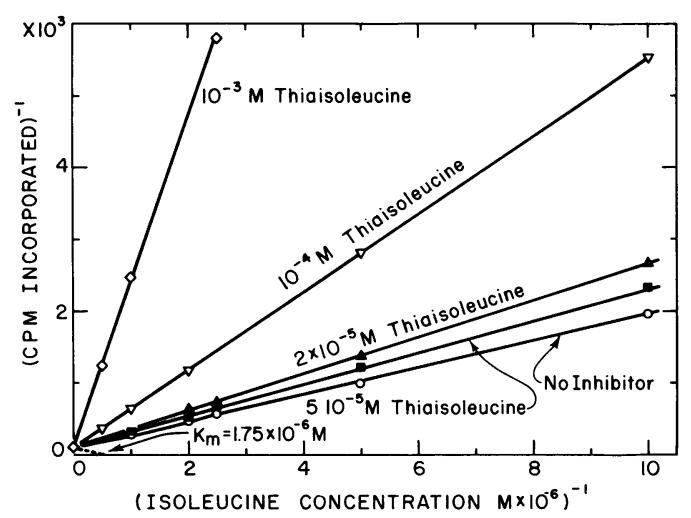

FIG. 5. Effect of thiaisoleucine on the charging of isoleucine soluble RNA by isoleucyl soluble RNA synthetase prepared from the thiaisoleucine-resistant mutant Tir-8.

TABLE 3. Isoleucine acceptor activity of wild-type and strain Tir-7 soluble ribonucleic acid ( $s R N A)$ charged with normal and mutant extracts

\begin{tabular}{|c|c|c|}
\hline \multirow{2}{*}{ Extract } & \multicolumn{2}{|c|}{ Specific activity ${ }^{a}$} \\
\hline & K-12 sRNA & Tir-7 sRNA \\
\hline $\mathrm{K}-12$. & 0.0016 & 0.0017 \\
\hline Tir-7 & 0.0002 & 0.0002 \\
\hline
\end{tabular}

${ }^{a}$ Expressed as micromoles per minute per milligram of protein.

tion, the precipitate was suspended in a mixture of $0.5 \mathrm{ml}$ of $0.1 \mathrm{M}$ acetate buffer $(p \mathrm{H} \mathrm{5.3)}$ and $0.5 \mathrm{ml}$ of $5 \mathrm{~mm}$ sodium periodate. After $30 \mathrm{~min}$ at room temperature in the dark, $2.5 \mathrm{ml}$ of ethyl alcohol was added. The precipitate was centrifuged, resuspended in $3.5 \mathrm{ml}$ of ethyl alcohol, and again centrifuged. The precipitate was suspended in $1 \mathrm{ml}$ of $0.2 \mathrm{M}$ glycine buffer ( $p \mathrm{H} \mathrm{10.3)}$ to "strip" any charged sRNA molecules present in the mixture. After $3 \mathrm{hr}$ at $37 \mathrm{C}$, the sRNA was again precipitated with ethyl alcohol and dissolved in sufficient $0.02 \mathrm{M}$ potassium phosphate $(p \mathrm{H} \mathrm{7.8)}$ to yield a concentration of $10 \mathrm{mg}$ of RNA per $\mathrm{ml}$ for use in the usual assay for isoleucyl or leucyl sRNA synthetase activity, with a crude extract as the enzyme source.

Charging of sRNA with either isoleucine or thiaisoleucine afforded some protection of the isoleucine acceptor activity against periodate oxidation (Table 4). In contrast, leucine acceptor activity after periodate treatment was no greater in the isoleucine- or thiaisoleucine-charged preparation than in the uncharged preparation. As might have been expected from the other observations on isoleucine and thiaisoleucine, the charg-
TABLE 4. Protection of isoleucine soluble ribonucleic acid ( $R N A)$ acceptor activity against periodate destruction by charging with L-isoleucine and thiaisoleucine

\begin{tabular}{|c|c|c|}
\hline \multirow{2}{*}{ Source of acceptor sRNA } & \multicolumn{2}{|c|}{$\begin{array}{l}\text { Radioactivity incorporated } \\
\text { (counts } / \mathrm{min})\end{array}$} \\
\hline & $\begin{array}{l}\text { Uniformly } \\
\text { labeled }{ }^{44 C} \text { C-L- } \\
\text { isoleucine }\end{array}$ & $\begin{array}{l}\text { Uniformly } \\
\text { labeled }{ }^{14} \mathrm{C}- \\
\text { L-leucine }\end{array}$ \\
\hline Original sRNA $\ldots \ldots \ldots$ & 30,940 & - \\
\hline Periodate-treated sRNA & & \\
\hline Uncharged . . . . . . . . . & 1,725 & 1,080 \\
\hline $\begin{array}{c}\text { Charged with } 3.3 \mathrm{~mm} \\
\text { L-isoleucine } \ldots \ldots\end{array}$ & 10,880 & 1,480 \\
\hline $\begin{array}{c}\text { Charged with } 33 \mathrm{~mm} \\
\text { thiaisoleucine } \ldots . .\end{array}$ & 8,200 & 1,180 \\
\hline
\end{tabular}

ing by thiaisoleucine was less, even though it was employed in a concentration 10 times as high as that of L-isoleucine.

\section{Discussion}

The thiaisoleucine-resistant mutants of $E$. coli described in this paper might be compared with the thiazolealanine-resistant mutants of Salmonella typhimurium described by Roth and Ames (12). One class of these mutants, hisS, has reduced levels of histidyl sRNA synthetase and, in minimal medium, has elevated levels of the histidine-forming enzymes. In addition to this class of mutants, there is another derepressed class (hisR) containing reduced levels of histidine sRNA (15). These observations, along with that of Schlessinger and Magasanik (13) that $\alpha$-methyl histidine inhibits histidyl sRNA synthetase and derepresses the histidine enzymes, show that histidyl sRNA formation is involved in the conversion of histidine to the hypothetical repressor of the histidine operon. While there is as yet no evidence that the formation of isoleucyl sRNA is an obligatory intermediate in the recognition of isoleucine as a repressor, the results described here show that at least activation by the synthetase is required.

That isoleucine must be activated (and perhaps transferred to sRNA) is of particular interest in view of the studies of Neidhardt and his colleagues (1) of a mutant containing a temperaturesensitive valyl sRNA synthetase. When this mutant was grown at nearly limiting temperatures, the enzymes in the isoleucine-valine biosynthetic pathway were derepressed. That both amino acids must be activated for repression is of interest in view of the fact that repression of the isoleucine-valine biosynthetic enzymes is multivalent (7). That is, derepression occurs if either isoleucine or valine is limiting or, as is now evident, if 
either the isoleucyl or the valyl sRNA synthetase is faulty. Although leucine is also involved in the multivalent repression of these enzymes, the one known class of mutations that results in the failure of leucine to participate in their repression (J. M. Calvo and H. E. Umbarger, Federation Proc. 23:77, 1964) does not appear to affect leucyl sRNA synthetase (M. Freundlich, personal communication).

In the case of valine, it may be that charging of the sRNA is also involved in multivalent repression. Recently, Freundlich (6) reported that supplementation of the medium of $E$. coli with $\alpha$-amino butyrate, an analogue of valine which, like $\alpha$-methyl histidine, inhibited the specific synthetase but was not itself transferred to sRNA, led to derepression. In contrast, supplementation with $\alpha$-amino- $\beta$-chlorobutyrate, which was transferred to valine sRNA, led to repression. (Experiments of this type, however, are difficult to interpret, since the failure of enzyme activity to increase could result from either repression or false protein formation.) As will be shown in the following paper (3), the addition of thiaisoleucine to cultures limited on isoleucine also prevented derepression. However, control experiments made it seem more likely that, rather than repression, there was either a generalized inhibition of protein formation or false protein formation.

That the thiaisoleucine-resistance mutation has been accompanied by derepression of only three of the five isoleucine-valine enzymes requires some comment. Since the acetohydroxy acid synthetase and isomeroreductase are not affected, it appears that isoleucine recognition is not required for repression of these two enzymes or that activation of isoleucine is not required. As will be demonstrated in the following paper, this pattern is, in fact, the pattern of multivalent repression in $E$. coli K-12 (3). Whereas all five enzymes are derepressed when valine and leucine are limiting, only threonine deaminase, dihydroxy acid dehydrase, and transaminase $\mathbf{B}$ are derepressed when isoleucine is limiting. It seems likely that the failure of acetohydroxy acid synthetase and acetohydroxy acid isomeroreductase to become derepressed when valine blocks isoleucine syn thesis, by inhibiting the activity of the synthetase (8), contributes to the inhibition of growth of $E$. coli $\mathrm{K}-12$ by valine.

It is of interest that the derepression pattern in the thiaisoleucine-resistant mutant was also found in a valine-resistant mutant of the K-12 strain by Ramakrishnan and Adelberg (11). It appeared that the lesion in that mutant was due to a mutation in the operator that affected the cluster of three genes corresponding to the enzymes that were derepressed. Although the derepression pat- tern is the same, there is the very important difference that the thiaisoleucine-resistant mutants described here are not valine-resistant.

\section{ACKNOWLEDGMENTS}

This investigation was supported by Public Health Service grant GM-12522 from the National Institute of General Medical Sciences. One of the authors (A. Szentirmai) was the recipient of a Ford Foundation Fellowship administered by the Institute for International Education.

\section{Literature Cited}

1. Böck, A., L. E. Faiman, AND F. C. NeIDHardT 1966. Biochemical and genetic characterization of a mutant of Escherichia coli with a temperature-sensitive valyl ribonucleic acid synthetase. J. Bacteriol. 92:1076-1082.

2. Dixon, M. 1933. The determination of enzyme inhibitor constants. Biochem. J. 55:170-171.

3. DWyer, S. B., AND H. E. UMBarger. 1968. Isoleucine and valine metabolism of Escherichia coli. XVI. Pattern of multivalent repression in strain K-12. J. Bacteriol. 95:1680-1684.

4. Eidlic, L., AND F. C. NeIDHARdT. 1965. Role of valyl-sRNA synthetase in enzyme repression. Proc. Natl. Acad. Sci. U.S. 53:539-543.

5. EzEKIEL, D. H. 1965. Requirement for p-fluorophenylalanine activation in control of ribonucleic acid synthesis. Biochim. Biophys. Acta 95:48-53.

6. Freundlich, M. 1967. Valyl-transfer RNA: role in repression of the isoleucine-valine enzymes in Escherichia coli. Science 157:823825.

7. Freundlich, M., R. O. Burns, and H. E. UMBARGER. 1962. Control of isoleucine, valine and leucine biosynthesis. I. Multivalent repression. Proc. Natl. Acad. Sci. U.S. 48:18041808.

8. LeAVITt, R. I., AND H. E. UMbarger. 1962. Isoleucine and valine metabolism in Escherichia coli. XI. Valine inhibition of the growth of Escherichia coli strain K-12. J. Bacteriol. 83: 624-630.

9. LoftField, R. B., And E. A. Eigner. 1966. The specificity of enzyme reactions. Aminoacylsoluble RNA ligases. Biochim. Biophys. Acta 130:426-448.

10. NeIDHARDT, F. C. 1966. Roles of amino acid activating enzymes in cellular physiology. Bacteriol. Rev. 30:701-719.

11. Ramakrishnan, T., and E. A. Adelberg. 1965. Regulatory mechanisms in the biosynthesis of isoleucine and valine. II. Identification of two operator genes. J. Bacteriol. 89:654-660.

12. Roth, J. R., AND B. N. AMEs. 1966. Histidine regulatory mutants in Salmonella typhimurium. II. Histidine regulatory mutants having altered histidyl-tRNA synthetase. J. Mol. Biol. 22:325-334.

13. Schlessinger, S., AND B. MagasaniK. 1964. Effect of $\alpha$-methyl histidine on the control of histidine synthesis. J. Mol. Biol. 9:670-682.

14. Shephardson, M., AND A. B. Pardee. 1962. 
Aspartate transcarbamylase from Escherichia coli, p. 925-931. In S. P. Colowick and N. O. Kaplan [ed.], Methods in enzymology, vol. 5. Academic Press, Inc., New York.

15. Silbert, D. F., G. R. FinK, AND B. N. . Ames. 1966. Histidine regulatory mutants in Salmonella typhimurium. III. A class of regulatory mutants deficient in tRNA for histidine. J. Mol. Biol. 22:335-347.
16. Stф The requirement for flavine adenine dinucleotide in the formation of acetolactate by Salmonella typhimurium extracts. Biochem. Biophys. Res. Commun. 17:587-592.

17. Szentirmai, A., aND H. E. UMbarger. 1968. Isoleucine and valine metabolism of Escherichia coli. XIV. Effect of thiaisoleucine. J. Bacteriol. 95:1666-1671. 